\title{
TOWARDS A STATISTICALLY LITERATE COMMUNICATION PROFESSIONALS
}

\author{
Cláudia Silvestre and Ana Meireles \\ ESCS - Escola Superior de Comunicação Social, Instituto Politécnico de Lisboa, Portugal \\ csilvestre@escs.ipl.pt
}

Communication professionals increasingly need to be able to read and critically comment on statistical data to communicate statistical information fittingly. Consequently, Statistics play an important role in the education of these professionals. Unfortunately, in Portugal most of the students who intend to become communication professionals do not feel at ease with numbers, mathematics or statistics. To engage our students and motivate them to learn, we have selected working groups themes related to their courses and used statistical information available in the real world. With this approach, we expect to get students more involved, make them familiar with using statistical information and let them increase their statistical skills. Therefore, everybody in the classroom, both students and teachers, are likely to become more motivated.

\section{INTRODUCTION}

Quantitative information is everywhere in society. We daily receive big amounts of statistic information via the media. The use of statistics is a practice, which is becoming increasingly common among communication professionals (journalists and advertising/public relations executives) to add credibility to advertisements, arguments, advice or to describe social phenomena and development (Ben-Zvi \& Garfield, 2004; Crompton \& Flanders, 2006; Gal, 2003). The media often use statistical terms such as mean, sampling, degree of confidence, margin of error that are assumed to be known by the general public (Gal, 2002; Sušec et al, 2014).

Citizens' statistical literacy is necessary so that individuals can decide whether the statistics presented are being used in a true way or as less clear representations of the reality. It is increasingly important to ensure that citizens are able to properly evaluate the information received to develop their critical sense for decision-making and identify biased or incorrect information (Campos, 2008; Gal, 2002; Helenius \& Mikkela, 2011; Sušec et al., 2014).

To overcome this situation, most countries have made meaningful changes in their curricula. Basic statistical concepts and procedures have been introduced, starting from the lowest schooling levels, allowing statistical thinking and competence in citizen formation (Ben-Zvi \& Garfield, 2004; Nikiforidou et al., 2010; Sušec et al., 2014).

If, on the one hand, citizens' statistical literacy is no doubt important, on the other hand it is also crucial that the development of statistical thinking and reasoning will keep up with the development of communication professionals. For example, for a report to have credibility, the journalist needs to examine information in various fields (political, economic, social phenomena ...), including numerical data analysis released daily. Likewise, the interpretation and utilization of the latest available business information (market trends, sales, audience ratings, ...) are fundamental for advertising and public relations executives to succeed and become competitive (Zandpour \& Rimmer, 2006).

The development of a solid working relationship between communication professionals and statistical agencies has become an increasingly urgent need, which does not stop growing. The communication professionals feel they have to use official statistical data to give credibility to their news but, as the other side of the coin, the statistical agencies have to use the media - press, radio and TV - to inform their readers about the official statistics (Crompton \& Flanders, 2006; Sušec et al., 2014). It is essential to let the future communication professionals realize the responsibility of press releases, since the contents they convey may affect the citizens' attitudes and behaviors. This information must be clear, non-ambiguous and maintain the legitimacy of official statistics in society.

Since we teach Statistics to Social Communications courses at university level, we often come across students that do not feel motivated to this subject or to related subjects, probably due to the specificity of their courses. At school and at university as well, they have been trying to escape everything that may remind them of Math and do not feel comfortable with the language used in this area. It is generally accepted that most of these students have negative perceptions and 
attitudes toward statistics and find them difficult and unpleasant (Crompton \& Flanders, 2006; Zandpour \& Rimmer, 2006). They do usually compare Statistics with Math and related subjects in secondary education in which they had to deal with concepts like fractions and algebraic formulas or abstract environment (Ben-Zvi \& Garfield, 2004).

It is common hearing "How can this concepts apply to day to day situations?" or "Even in university we keep being "haunted" by numbers!" and this reflects the students disillusion regarding statistics. To try to revert this negative attitude we seek showing them the importance that statistic has on their day to day as communication professionals.

As many authors, (Ben-Zvi \& Garfield, 2004; Zandpour \& Rimmer, 2006) we also recognize that unmotivated students will be those who are more likely to get worse results and easily forget what they have learned (Swanson \& McKibben,1998). One of out biggest challenges consists on making the classes "appealing" and mainly transmit the statistical thinking and reasoning that will be fundamental for their success as communication professionals. The simulation of real-life professional activities like developing promotional campaigns or editing a report about a current problem using real data may be a technique to use to improve advertising or public relations students attitude toward statistics (Zandpour and Rimmer, 2006).

According to Forbes et al. (2011), the statistical investigation process should consider five phases: problem, plan, data, analysis and conclusion. A clear definition of research problem and questioning and planning are fundamental tasks in this process. Due to work time constraints it is often impossible for students to be able to collect their own data. In these cases, it is necessary to analyze which real databases are available (on the Internet or through their own bodies) to analyze the problem. These tasks are usually performed with some ease by the media students, given their willingness to deal with technological resources.

The available informatic means and the software with menus of simplified access have been fundamental for the teaching of this discipline. They allow the achievement of results suppressing the need for learning algorithms and procedures or the domain of mathematical concepts that may underlie them (Pimenta, 2006; Swanson \& McKibben, 1998). Although technologic support make the teaching of statistics less focused on computational mechanics, there should be an awareness by teachers of the danger of only teaching software instead of teaching statistics (Pimenta, 2006).

However the problem persists! It is relatively easy to "build statistics," but lack of statistical literacy can lead to incomplete or erroneous readings of the data.

Our goal is to train communication professionals statistically literate. Our aim is for them to acquire basic statistical concepts and resources that allow them to organize the data through tabular displays or adequate graphical representations. This type of resource is often used to complement statistical reports. Graphical representations become easier for the general population to interpret (Forbes et al., 2011).

The approaches we take intend to encourage students to develop statistical thinking and reasoning. Our main goals are develop the ability to interpret and evaluate statistical outcomes which cannot be seen as only numbers, emphasize that the analysis should be done taking into account the context of the study, how the data were collected, the purpose of the study, and limitations imposed by the data-gathering process on possible conclusions.

\section{METHODOLOGY}

This project was carried out at ESCS - Escola Superior de Comunicação Social (School of Communication and Media Studies) in Lisbon, and involved students from two different courses: Public Relations and Journalism. Each course has its own statistical needs. Public Relations (PR) professionals use statistics to make decisions. These professionals need to understand, make assessments with criticism and be capable to explain statistical results to their employers and clients, or to write a press release (Gal, 2003), for example. While Journalists need to interpret data, choose the best way to represent them and be able to communicate statistical information to their audience.

Therefore, it is clear that we need to have different approaches according students' needs, but in both cases, these professionals should communicate meaningful, useful, and accurate information. In order to achieve these goals we promote effective learning (Watkins et al., 2007) 
and during our classes, we used real-data, which increase students' motivation (Ograjenšek \& Gal, 2016).

In both cases, we used a document called Best Practices Guide for Use of Statistical in Public Relations (PRS \& ASA, 2011), developed by Public Relations Society and the American Statistical Association. This document aims to help professionals who must understand, interpret and communicate statistical issues. We used it to highlight some aspects that should be taken into account when analyzing statistical outcomes. For example, be sensitive to data quality, identify the aims of the investigation, recognize the limitations of the study, analyze the sample of the survey, and be aware that all statistical research deals with some level of uncertainty. Curiously, these tips were most useful for journalism students' project.

\section{Public Relations Project}

For Public Relations students, under the theme of the second World Statistics Day - Better data. Better life - we discussed the main ideas and identify three sub-themes that each group should research: the first records of the use of statistics and their objectives, the importance of using statistical information for PR professionals, and collecting, processing, and presenting statistical information about ESCS. Each working group chose a sub-theme. There was more than one group working on the same sub-theme. The groups that worked on last sub- theme had a follow-up; they needed help in data collection and in statistical analysis to choose the best way to describe the data.

Each working group presented the results of their research to the teacher, who made a brief evaluation of the work and could decide that: the work was finished, the work needed minor adjustments or the work needed specific orientations in order to improve it. At the end, each group written a small report that should not exceed one page. A teacher made the compilation of all these reports as well as some necessary adjustments.

After compilation, all students read their report and the report of their colleagues in order to (1) understand how the adjustments made by the teacher contributed to the improve their work, (2) when reading colleagues report on the same sub-theme, get another point of view on the same subject or see another way of representing the same information, and (3) learn about other subthemes.

\section{Journalism Project}

We had another approach for Journalism students, we presented the main conclusions of the research developed by Pereira et al (2015) that focuses on mathematical errors in the news, particularly in its incidence and typology (numerical error or statistical error). The authors analyzed a sample of 7,717 news from three Portuguese daily newspapers, they identified the news, which had mathematical content and found that $33.4 \%$ of them had errors, but they did not give any example.

After presenting the statistical results of this research, we show few examples of news from our media, which involve data analysis, and in classroom, we examine in detail the available statistical information. From this analysis emerges a list of topics that should be taken into account in future analyzes (fig. 1). For more detailed guidelines to help students when they are analyzing statistical news, see for e.g. (Gelman et al, 1998).

\begin{tabular}{|ll|}
\hline$\checkmark$ & Does news report official statistics? \\
$\checkmark$ & What is the nature of the data? \\
$\checkmark$ & Does the news have details about the data? \\
$\checkmark$ & What is graph scale? Is it starting at zero? \\
$\checkmark$ & Would additional graphs be helpful? \\
$\checkmark$ & Do you remove, change or add any sentence? \\
$\checkmark$ & Does news communicate clearly?
\end{tabular}

Figure 1: Checklist for analysis of news with statistical information.

The next step was asking students to find news with statistical information. First students analyze one or two news in small groups, each group works with the news of their own choosing. 
Then the news are discussed with all class according to the previous checklist and other topics that students may have found interesting when they were reviewing their news. Our goal at this stage is to introduce a way of thinking - thinking statistics in these classes. We are not interesting in just criticizing a news, but it is about the role of statistics in making decisions and its relevance for our society.

\section{RESULTS}

Involving the students in a commemorative statistics day, or analyzing news from our media with them bring statistics to real life, a context that has meaning which encouraged students to be participative and made them more receptive to learn. These approaches also provided the opportunity to stimulate debate, action in statistical field, and emphasized the power of critical thinking.

One of the students research under the sub-theme using statistical information for PR professionals was about Moneyball. Moneyball tells the story of how Billy Beane the manager of Oakland Athletics baseball team used rigorous statistical analysis to gain an advantage in assembling and managing his baseball team successfully. There is a book and a movie about it. It was interesting discuss the main ideas of this phenomenon with the class. As teachers, we ignored this phenomenon, so for us it was also surprising.

Due to communication strand of public relations course, some students chosen to present their results in a more creative way. Some groups made posters and other used cartoons, which were focused on main conclusions of their research. A compilation of their reports is available at http://repositorio.ipl.pt/bitstream/10400.21/5684/1/boletim 5.pdf.

It was interesting to note that many journalism students have concluded that the news are not true. Usually when they read news they did not question the nature of the data presented and thought they referred to the population rather than a sample. During this research, they realize that the majority of studies are based on samples and in many cases is not given any information about how the sample was chosen, so we cannot perceive its representativeness. Hence, they have concluded that the news may not be true.

When they were looking for news with statistical information, they found a lot of them about economic issues. In addition, they conclude that this news usually use official data and they have graphs to represent or illustrate key ideas but it was not easy to go further in the analysis due to terse language and unfamiliar contexts. So economic news had a more superficial analysis comparing the ones referring to other subjects.

After their research journalism students learned how to carefully a news should be read and using real-world problems contributed to students learn much more about the relevance of statistical methods in our society including data collection.

\section{CONCLUSIONS AND FUTURE RESEARCH}

With our approaches the students can understand why statistics is useful in their professional lives. Students' motivation is an important factor to consider when we are teaching. So using different approaches for each course allow students to choose the subject to investigate which contributed to be more motivated with their working groups, and we hope that it will also help them to retain much of which they learned in class. In both courses, these approaches promoted debate and action in statistical fields, as a consequence, reduced anxiety (mathematics anxiety) when dealing with statistical information.

It is clear that we, as teachers, need to find the way to improve statistical education. We think that these different approaches contributed to this goal. In the future we would like to try other approaches involving real data. In that sense, the work developed by Gal (2003) which is focuses on the benefits of using press releases to promote students" statistical literacy, inspired us. Like the author, we will select press releases that can be used in classes to develop students' communication skills and to improve the way they report and analyze outcomes. 


\section{REFERENCES}

Ben-Zvi, D \& Garfield, J. (2004). Statistical Literacy, Reasoning; Goals, Definitions and Challenges. In D. Ben-Zvi \& J. Garfield (Eds.), The challenge of developing statistical literacy, reasoning, and thinking (pp. 3-15). Dordrecht, the Netherlands: Kluwer Academic Publishers.

Campos, P. (2008). Thinking with data: The role of ALEA in promoting statistical literacy in Portugal. Government Statistical Offices and Statistical Literacy. Available at $\mathrm{http} / / /$ citeseerx.ist.psu.edu/viewdoc/download?doi=10.1.1.443.9473\&rep=rep1\&type=pdf

Crompton, V., \& Flanders, J. (2006). Communicating statistics to the media: Telling the story behind the numbers. Available at https://iaseweb.org/documents/papers/icots7/1A2_CROM.pdf

Forbes, S., Camden, M., Pihama, N., Bucknall, P., \& Pfannkuch, M. (2011). Official Statistics and statistical literacy: They need each other. Statistical Journal of the IAOS, 27(3, 4), 113-128.

Gal, I. (2002). Adults' statistical literacy: Meanings, components, responsibilities. International statistical review, 70(1), 1-25.

Gal, I. (2003). Functional demands of statistical literacy: Ability to read press releases from statistical agencies. IASE Berlin. Available at https://iaseweb.org/documents/papers/isi54/3016.pdf

Gelman A., Nolan D., Men A., Warmerdam S. \& Bautista, M. (1998). Student Projects on Statistical Literacy and the Media. The American Statistician, 52 (2), 160-166.

Helenius, R., \& Mikkelä, H. (2011). Statistical literacy and awareness as strategic success factors of a national statistical office-the case of Statistics Finland. Statistical Journal of the IAOS, $27(3,4), 137-144$.

Nikiforidou, Z., Lekka, A., \& Pange, J. (2010). Statistical literacy at university level: the current trends. Procedia-Social and Behavioral Sciences, 9, 795-799.

Ograjenšek, I. \& Gal, I. (2016). Enhancing Statistics Education by Including Qualitative Research. International Statistical Review, 84 (2), 165-178.

Pereira, S., Azevedo, J. \& Machiavelo, A. (2015). A matemática na imprensa diária portuguesa. Literacia, Media e Cidadania - Livro de Atas do $3^{\circ}$ Congresso, Braga: CECS, 516 -523.

Peter, K., \& Kellam, L. (2013). Statistics \& the Single Girl: Incorporating Statistical Literacy into Information Literacy Instruction. LOEX Quarterly, 40(1), 2.

Pimenta, R. (2006, July). Assessing statistical reasoning through project work. In Proceedings of the ICOTS7-Seventh International Conference on Teaching Statistics. Available at https://www.stat.auckland.ac.nz/ iase/publications/17/C117.pdf

PRS \& ASA - Public Relations Society \& American Statistical Association (2011). Best Practices Guide for Use of Statistics in Public Relation. Available at http://apps.prsa.org/Intelligence/BusinessCase/Documents/StatisticsBestPracticesGuide.pdf

Sušec, M. P.; Muravec, N. J. \& Stančić, H. (2014). Statistical Literacy as an Aspect of Media Literacy. Medijska istraživanja. 20(2), 131-155.

Swanson, D. A. \& McKibben, J.N. (1998). On teaching statistics to non-specialists: a course aimed at increasing both learning and retention. In International Association for Statistical Education. Available at https://iase-web.org/documents/papers/icots5/Topic2g.pdf

Watkins, C., Carnell, E. \& Lodge, C. (2007), Effective Learning in Classrooms. London: Sage Publications.

Zandpour, F., \& Rimmer, T. (2006, July). Media Studies and Statistics: Real-world Demands, Classroom Quandaries, and On-line Solutions. In International Conference on Teaching Statistics, Salvador, Brazil (pp. 2-7).

Available at https://iase-web.org/documents/papers/icots7/8A1_ZAND.pdf 